\title{
A Proposed Crowdsourcing Cadastral Model: Taking Advantage of Previous Experience and Innovative Techniques
}

\author{
Sofia Basiouka* and Chryssy Potsiou ${ }^{\dagger}$ \\ *National Technical University of Athens, s.basiouka@gmail.com \\ ${ }^{\dagger}$ National Technical University of Athens
}

\begin{abstract}
Are Land Owners able to participate in official Cadastral Surveys? Can the official procedures be modified in order for crowdsourcing techniques to be incorporated in them? How many different stakeholders can actively get involved and which is the optimum workflow that could be adopted? This chapter addresses the main question of whether the spatial and attribute data that is collected by volunteers - land owners - can be used in official Land Administration Systems (LAS) and explores the potential introduction of crowdsourcing techniques into the official cadastral surveys as a simplified and transparent procedure with the aid of citizens.

As the title reveals, this chapter aims to propose a crowdsourcing cadastral model as an alternative option to the official cadastral procedures. The research investigates a voluntary model and documents it in terms of participants and structure according to various international case studies that were analyzed in depth within the research that was carried out by Haklay et al. (2014). The main lessons that were collected by each separate crowdsourced case study were used as a guideline for the suggested cadastral model. The opportunities and the weaknesses are isolated and explored in terms of a cadastral survey. The main advantage of the adopted case studies is the opportunity for a simulation of

\section{How to cite this book chapter:}

Basiouka, S and Potsiou, C. 2016. A Proposed Crowdsourcing Cadastral Model: Taking Advantage of Previous Experience and Innovative Techniques. In: Capineri, C, Haklay, M, Huang, H, Antoniou, V, Kettunen, J, Ostermann, F and Purves, R. (eds.) European Handbook of Crowdsourced Geographic Information, Pp. 419-433. London: Ubiquity Press. DOI: http://dx.doi.org/10.5334/bax.ad. License: CC-BY 4.0.
\end{abstract}


real circumstances in cadastral surveys and not a simplistic logic. The main innovation is focused on the design of the model in an a priori approach with well-defined and already tested successful case studies.

The model is clarified in technical and societal aspects while it sheds light on the proposed process. The workflow, the stakeholders and the adopted main lessons of the crowdsourced case studies are the key components that are explored and analyzed in this chapter.

\section{Keywords}

Volunteered Geographic Information, Crowdsourcing, Cadastre, Land Administration \& Management, Spatial Data Infrastructure.

\section{Introduction}

The great revolution that has taken place in Geographic Information Science (GIS) has led to dramatic changes in the source, use and manipulation of spatial information during the last decade. Seeger (2008) and others name it 'the digital spatial data which is collected and edited not by data producers but by citizens who are not experts but willing to disseminate their spatial knowledge and observations' without any special invitation. Blaut et al. (2003) had earlier noted the specific predisposition of all human beings to map by underlining that all people have natural mapping abilities. According to Kingsley (2007), civil society shares the same goals and has created a non-hierarchical network of self-organized individuals who participate in it. In fact he predicted the evolution of mapping, the involvement of amateurs with the aid of web tools and the alteration of role distribution between mapping agencies and users (Budhathoki et al. 2008). Three principle definitions were introduced to give a general title to the phenomenon; Neogeography, Volunteered Geographic Information and Crowdsourcing. Turner (2006) refers to Neogeography as a set of techniques and tools that fall outside the realm of traditional GIS. Goodchild (2007) coined the term Volunteered Geographic Information (VGI) which is one of the most widely deployed and disseminated terms and Sieber (2007) refers to Crowdsourcing in the way that it is currently used. All terms investigate GI and find innovative adjectives to shed light on different aspects of the phenomenon, which can be simply understood as voluntary manipulation of spatial data by citizens.

Within the new web-based era and the great possibilities offered to users via dynamic maps and new technologies to manipulate data, another field presents great interest due to its socio-economic perspectives. Land Administration is a relatively new term, which was introduced in the 1990s. Theoretically, Land Administration is defined as the process of determining, recording and disseminating information about the tenure, value and use of land when implementing land management policies (UNECE 1996). Many academics have 
investigated Land Administration and have contributed to various aspects of the field. Dale and McLaughlin (1999), Williamson (2001) and Bogaerts et al. (2002) are just a few of the academics contributing to this field.

Cadastre is a significant part of Land Administration and has various definitions according to different scientific sources. The United Nations (in 1985) and the International Federation of Surveyors (FIG) (in 1995) gave the predominant definitions. The former underlines that 'the cadastre is a methodically arranged public inventory of data on the properties within a certain country or district based on a survey of their boundaries; such properties are systematically identified by means of some separate designation. The outlines of the property and the parcel identifier are normally shown on large-scale maps' (UN, 1985 In: Steudler, 2004: 13). The latter notes, 'A cadastre is normally a parcel based, and up-to-date land information system containing a record of interests in land (e.g. rights, restrictions and responsibilities). It usually includes a geometric description of land parcels linked to other records describing the nature of the interests, the ownership or control of those interests, and often the value of the parcel and its improvements"' (FIG 1995 In: Steudler, 2004: 14). The need for an accurate and up-to-date cadastral system is so vital that Kaufmann and Steudler (1998), in their publication 'Cadastre 2014', support the inclusion of public and traditional law aspects in the definition given by FIG in 1995 .

Cadastral survey according to Steudler (2004: 14) is 'simply defined as a survey of boundaries of land units'. Generally, cadastre is an essential tool for land management and administration as it records the land parcels which constitute a part of a country's spatial information infrastructure. The Bogor Declaration on Cadastral Reform (UN-FIG 1996) in other words declared that the development of modern cadastral infrastructures facilitate efficient land and property markets, protect the land rights of all, and support long term sustainable development and land management. It also facilitates the planning and development of national cadastral infrastructures so that they may fully service the escalating needs of greatly increased urban populations.

The main question that is posed in this chapter, taking into consideration all the above perspectives on technology and potential scenarios, is whether VGI and crowdsourcing techniques more generally can be incorporated in cadastral surveys and to what extent. The testing of the results is done through the Hellenic Cadastre project, which is a well-known, long-lasting project. The idea of incorporating VGI into the cadastral procedure is based on the power of locality and the participation of citizens in land planning as active parts of society.

\section{The official cadastral procedure}

The HC Project started in 1995 and cadastral surveys have been carried out in 340 regions all over the country while 106 cadastral offices have already 
begun operations in these regions. The responsible agency for the $\mathrm{HC}$ project is the National Cadastre and Mapping Agency S.A. (NCMA S.A.). The Hellenic Cadastre is a uniform, public, systematic and on-going title registration information system in fully digital form with spatial and attribute records of each land parcel. Before investigating on the alternative crowdsourced proposal, an overview of the official procedure is thoroughly presented.

The main cadastral survey includes the following stages (Basiouka \& Potsiou 2012) (Figure 1):

- Declarations are submitted to the cadastral survey offices by the right holders and the registration of the declared rights is added to a digital database.

- Interim cadastral tables and diagrams are formed based on the data from the submitted declarations, which has been processed by lawyers and surveyors.

- Interim cadastral maps and data are published for a two-month period and extracts are sent to the rights holders for their information and acceptance.

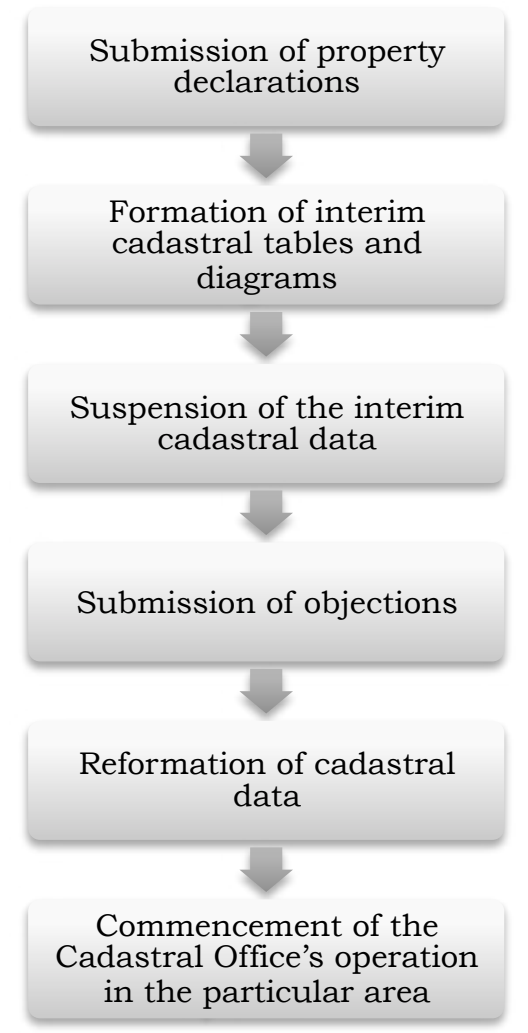

Figure 1: Main Cadastral Stages. 
- Objections or applications for correction of a cadastral registration are submitted and forwarded to independent administrative committees, depending on the case, by whoever has a legal right.

- The cadastral data is reformed after examination of the objections and the correction claims and the final cadastral tables and diagrams are formed. These registrations are called Initial Registrations and they constitute the first registration in the Hellenic Cadastre.

- The cadastral office in operation in the particular area replaces the old Land Registry Office (NCMA 2011).

Given that the official process, according to Greek legislation, is based on a core scientific number of stages where surveyors, lawyers and IT technicians are the ones to collect, edit, store and handle data, the proposed idea has proven somewhat innovative. To date, citizens are excluded at all stages, except from the declaration of their private property at the beginning of the process.

\section{The Proposed Crowdsourcing Cadastral Model}

The proposed crowdsourced model for cadastral surveys is the result of the main lessons that have been collected from a series of successful governmental crowdsourced projects that were analyzed in depth (Haklay et al. 2014); the requirements posed by the nature of a cadastral project; the innovative ideas the researcher has decided to introduce; and the necessity for coordination with formal cadastral procedures and realities. As previous research carried out by Haklay et al. (2014) indicated, the key factors for a successful crowdsourcing experiment include building on previous experience, leveraging existing technology and having the support of key partners such as governments or other authorities. The proposed model aims to take advantage of previous experience of official procedures and to introduce innovative techniques that will facilitate them.

The structure of the proposed model is divided into four main sections: the adopted main lessons identified from the successful case studies, which will be incorporated in various parts of the model: the proposed workflow, which will replace the official procedure; and finally the participants and stakeholders of the project. The aim of the research is to launch a model that may be applied and used either at a local or a national level; and it may have a wider application in many countries and communities that face land issues.

\section{The successful crowdsourced case studies}

The research on the successful case studies was carried out by Haklay et al. (2014). An investigation was made of the incentives, scope and aims behind the practical experiments; their participants and stakeholders; their relationships 
and the modes of engagement. The research also shed light on technical aspects, successful factors and the problems that were encountered in the evaluation of the examples.

Each case study is intended to provide an example of the use of VGI by government or by the public, and summarizes the context, positive and negative outcomes and main lessons. The focus of 6 case studies is divided into three main categories: land management, public administration and disaster response. Although the case studies are differentiated by content and scope, all of them are governmental projects that incorporate voluntary and crowdsourced data collection, so their study can isolate those components that are crucial for the success of the current project. The main lessons derived from the case studies and the outcomes are described briefly below, with text taken from Haklay et al (2014, CC-BY):

Mapping of South Sudan This was launched because of the need for a temporally accurate and up-to-date map when the new nation was created. Google Map Maker, the Sudanese diaspora and various organizations carried out workshops to train people to work separately on the digitization of aerial imagery. A significant amount of work was completed in a very short amount of time by adopting local knowledge and providing technical tools. Those who experienced the training sessions were inspired to transmit the experience and recruit new volunteers.

\section{Main lessons:}

- Crowdsourcing projects can be coordinated and implemented from a distance.

- Great participation of volunteers and transmission of motivation to others are key factors in terms of participation in crowdsourcing applications.

Informal settlement mapping, MapKibera, Nairobi, Kenya. Map Kibera was carried out in the most crowded slum in Nairobi, Kenya, in an effort to improve its reputation and offer an accurate picture of the area, which is quite dynamic due to the movement of the population. Local people collected and edited GPS tracks. Innovative techniques such as SMS, video and voice reporting were also launched and a small amount of compensation offered to participants.

\section{Main lessons:}

- Mapping can be achieved by young local people relatively quickly.

- Basic topographic maps can be enhanced with essential thematic layers.

- A combination of open source and conventional software can facilitate VGI projects.

- Compensation may be needed to improve participation in locations where participants suffer great survival issues.

- Innovative methods such as SMS, voice and video reporting can support the appeal of mapping projects. 
Crowdsourcing The National Map, National Map Corps, US. National Map Corps has given volunteers the choice to collect and edit data about ten different human-made structures in fifty states in an effort to provide accurate and authoritative spatial data. The methodology includes various steps such as adding new features, removing obsolete points and correcting existing data. A pilot test in Colorado showed that the VGI was satisfactory in its accuracy.

\section{Main lessons:}

- Adoption of challenging techniques such as gamification has been successful and attracts volunteer interest.

- Evaluation of the quality indicated that the participation improves accuracy and reduces the errors.

- Organizational resistance to accepting data from volunteers is one of the major challenges for VGI projects of this kind.

- Key factors to successful crowdsourcing include building on past experience, leveraging existing technology and having the support of key individuals within the organization.

iCitizen, mapping service delivery, South Africa. This project is at the design phase and aims to involve the public at a local level to collect data points via mobile phones and adopt different ways for geotagging of photos in real time or via SMS and email. The purpose is to report infrastructure issues.

\section{Main lessons:}

- Projects can be used for a variety of tasks at local level, not just that for which they were designed.

- Using a range of software, programming languages and platforms can broaden a project's horizons.

- VGI applications face financial issues due to their nature and the resources of the organizations involved.

- Concerns from agencies about the quality of generated data sets and improving public adoption of mobile applications are common challenges.

Haiti disaster response. One of the most well-known crowdsourcing applications, developed after the earthquake hit Haiti in 2010. Within 48 hours, the capital was mapped by volunteers who contributed from every part of the world to create an up-to-date topographic map to fill the gap left by the official mapping agency. The maps were used by various organizations to allocate supplies and medicine.

\section{Main lessons:}

- An integrated methodology of this kind follows four steps: spatial data contributed by official providers, supplemented with GPS tracks, integrated 
into OpenStreetMap and updated by a great number of volunteers from each part of the world.

- Time, cost and official trust of data by Non-Governmental Organizations (NGOs) and other official partners are key to success.

- Lack of coordination and experience between different actors can lead to duplication of data and waste of resource.

- Differentiation between conventional and governmental data in terms of engagement to the project did not prevent success.

Community Mapping for Exposure in Indonesia. The goal of this project is to reduce vulnerability to natural disasters. Young people have successfully collected spatial and attribute data, and traced them in the OSM platform so that thematic maps can be created to show potential damage in case of physical disasters.

\section{Main lessons:}

- Interaction between official providers and VGI is a parameter of success not only for the beginning of the project but also for its continuity.

- Open source data can be reliable for scenario building but its quality can vary, especially in terms of attribute data.

- The coordination of participating organizations and volunteers is important to take full advantage of human resources and technical innovations.

\section{The main lessons adopted}

Within the specific alternative proposed model for cadastral surveys, a series of main lessons, technical aspects and successful factors are adopted as vital for the viability of the model. The majority of them serves the nature of the research and plays a crucial role in its design. The predominant key factors are given below and are explained in terms of the proposed cadastral model.

- Training and workshops should take place at the beginning of each application. Most of the practical applications that constitute successful crowdsourced paradigms - such as Community Mapping for Exposure in Indonesia, MapKibera in Kenya and mapping of South Sudan - introduced workshops as a key factor for their success. This is of vital importance due to the technical requirements of a cadastral survey and the quality controls that should be satisfied at the end of any project. The workshops have three different targets: (a) to inform locals about the necessity and benefits of the project, (b) to recruit them and (c) to train them to properly manipulate spatial and attribute data.

- Recruitment of volunteers. Except for local people - land owners who will play a vital role in data collection - the proposed model is based 
on non-governmental organizations and undergraduate students of the schools of Surveying, Geography or any other relevant field. Both will keep the cost low and the students will support the cadastral surveys both practically and technically. The undergraduate students will participate actively in the data collection and editing. The idea for this came accidentally due to the nature of the study, however, Community Mapping for Exposure in Indonesia had already recruited undergraduate students to collect a huge amount of data in a relatively short time and scholarships were offered in exchange. The idea behind the recruitment of non-governmental organizations is to carry out all workshops at the beginning of the process. Students should also deal with the great amount of data that should be collected and manipulated. The main question over the participation of land owners as volunteers is in terms of their motivations. Land owners may be more easily recruited if cadastral fees were eliminated, or similar taxation rates lowered, as a result of their participation. Experience from other countries has indicated that the incentives that lead volunteers to participate in crowdsourcing projects are a mixture of various parameters. The land owners will participate voluntarily for altruistic reasons if they recognize the necessity of the project, how their lives will be affected by its implementation and how their properties will be protected. This is especially the case for those who face difficulties in land transactions, use and development. However, the majority will be motivated if a compensation rate is offered to them.

- Partnership with scientific organizations. Collaboration between the various organizations is proposed within a well-defined and compact pattern where the roles and duties are made clear from the beginning of the procedure. To avoid the lack of coordination and duplication of data noted in Haiti disaster response, each stakeholder should be responsible for a specific part of the cadastral survey and all the participants should work in cooperation in order to produce the final result. Supervision and quality controls should also be carried out by experts. The main innovation of the project, which has a national application, is based on the participation of various NGOs at local level. The NGOs that take action at local level should be responsible and should participate actively in the cadastral surveys in these areas.

- Crowdsourcing projects can be coordinated and implemented from a distance. The importance of this keynote is crucial for the success of the first phase of the cadastral survey where citizens should digitally declare their ownership from a distance instead of hard copy declarations and indicating their ownership on digital orthophotos at the cadastral offices. The phase may be carried out in digital form and implemented from a distance. The attribute data declaration may be replaced by an online declaration with the aid of Apps or online tools and the field work for spatial data collection in urban areas can be replaced by the online digitization of land parcels on orthophotos provided by the website of the official mapping 
agency or on OSM. This specific strategy worked efficiently in the mapping of South Sudan.

- Open - source and commercial software should be used because experience has indicated that their combination offers the required freedom and openness for the project. The informal settlement mapping in Nairobi, Kenya, flourished with the aid of open-source and conventional software. Open-source software may be used in data collection while conventional software may be used in data manipulation. The contribution of volunteers in data collection requires the use of flexible and easy-to-use tools. The editing of data demands advanced functionalities that may be available only in conventional GIS software packages. Previous experience has indicated that using a range of software, programming languages and platforms may broaden a project's horizons.

- Innovative techniques. In an effort to meet the requirements of the project, especially in terms of quality, a series of innovative techniques have been adopted in data collection and manipulation. For the first time, OSM is tested for use in data manipulation and storage in cadastral surveys. Also, smartphones and handheld GPS gradually replace the expensive equipment that is needed for data collection. All these innovations were introduced to propose an alternative, viable solution to the official procedure.

\section{The Workflow}

The workflow of the proposed model follows a general pattern that includes all different occasions of mapping in rural or urban areas, and it constitutes of four main steps. The proposed model may be applied at the beginning of a cadastral survey and it may replace the first phase of official cadastral mapping. The hard copy declaration of ownership, the identification on orthophotos of properties in the rural areas and the acceptance of the produced result are only a few stages of the official process that may be modified. Although the procedure may be categorized in these four stages, it may include further parameters that are identified within practical experiments (Figure 2).

Training of volunteers is the first step of the process. The NGOs and the undergraduate students will train the land owners both theoretically and practically. The award for the participation of students will be in the form of scholarships and work experience.

Data collection as the second step of the workflow differs depending on the nature of the area and the kind of data that should be collected. Rural areas require a different approach in comparison to urban ones while spatial data collection requires different tools to attribute data. Data in rural areas may be collected by using handheld GPS devises, tablets or smartphones while in 


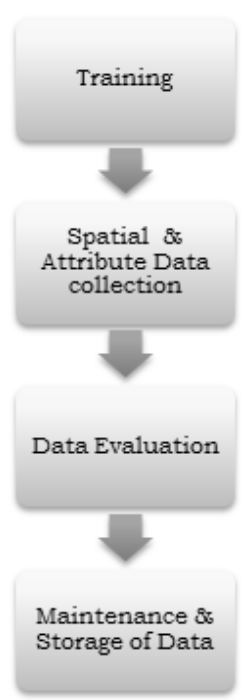

Figure 2: The workflow of the proposed Cadastral Model.

urban areas by using accurate orthophotos provided via the website of the official mapping agency or various online maps such as OSM in case of a lack of other accurate basemaps.

In rural areas, the citizens may either declare their ownership by giving the point of its centroid (Figure 3, right) in a quick and inexpensive approach or collect their parcel boundaries (Figure 3, left) with expert support after been trained. Both approaches fit in interim cadastral mapping. The methodology may vary depending on parcels' shape.

In urban areas, citizens can simply declare their ownerships by using online tools and orthophotos as basemaps which are provided via the website of the official mapping agency or online dynamic maps such as OSM. The choice depends on the availability of the recourses. The experience has indicated that OSM can be adopted for cadastral purposes, taking into consideration specific generalizations and rules (Basiouka et al. 2015).

The attribute data collection can be also implemented with the aid of online databases, which can store and maintain the saved information so that the hard copy declaration to be replaced.

Data evaluation, as the third step of the workflow, should be guaranteed by the national mapping agency, which will also be responsible for the maintenance and storage of the data in its servers. Thus, one of the most important concerns in terms of viability - the difficulty of keeping data up to date - can be bypassed. 


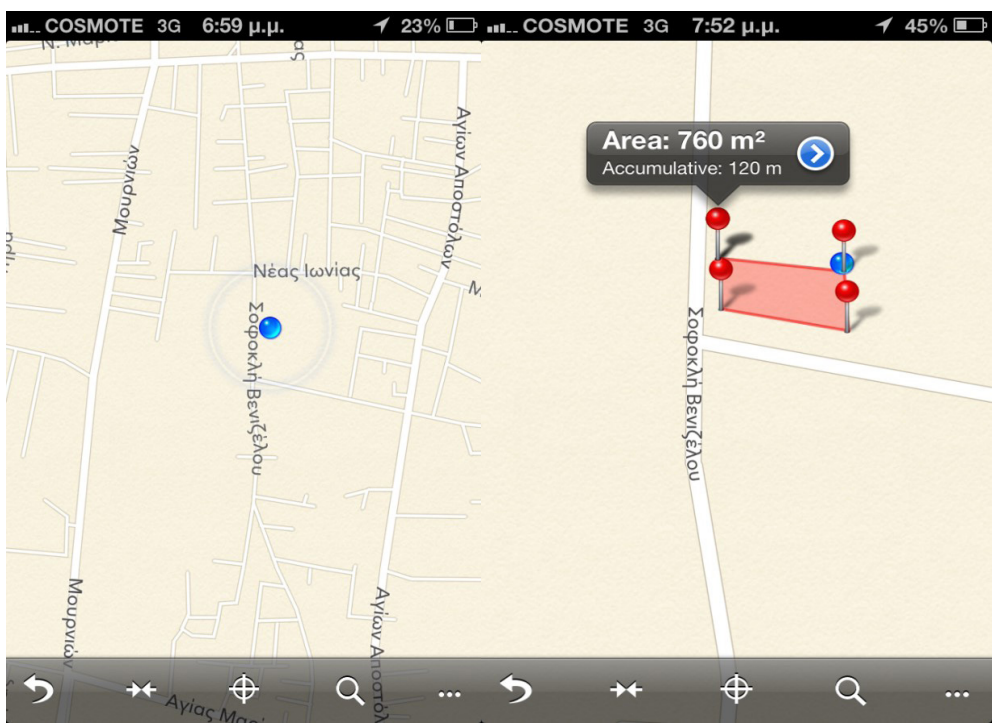

Figure 3: Different approaches in spatial data collection.

\section{The Stakeholders of the Model}

The model is based on the participation of citizens in a hybrid approach where citizens and property owners participate as volunteers and experts work as team leaders supervising the whole process. Thus, the hybrid approach involves both amateurs and experts for its implementation. In order to be successful, it requires the participation of locals, experts and NGOs, while the coordination of these parties should be carried out by the official mapping agency. Specific parts of the public sector should also participate in certain parts of the procedure (Figure 4).

The term 'locals' refers to the land owners and volunteers who will participate in the cadastral surveys. Their participation should be based on data collection and editing during the first steps of the process and the acceptance of the result at the end of the cadastral survey. Citizens may collect not only spatial but also attribute data. The locals constitute the base of the pyramid that is given in Figure 4.

The next level of the pyramid refers to the NGOs who will train volunteers in data collection and editing. Their coordination highlights another important parameter: the cooperation of participating organizations and volunteers is crucial for the full advantage of human resources and technical innovation. Their interaction is also a parameter of success required not only at the beginning of the project but throughout.

Furthermore, the public sector should act to supplement these actors and provide the required equipment such as GPS and total stations, computers, 


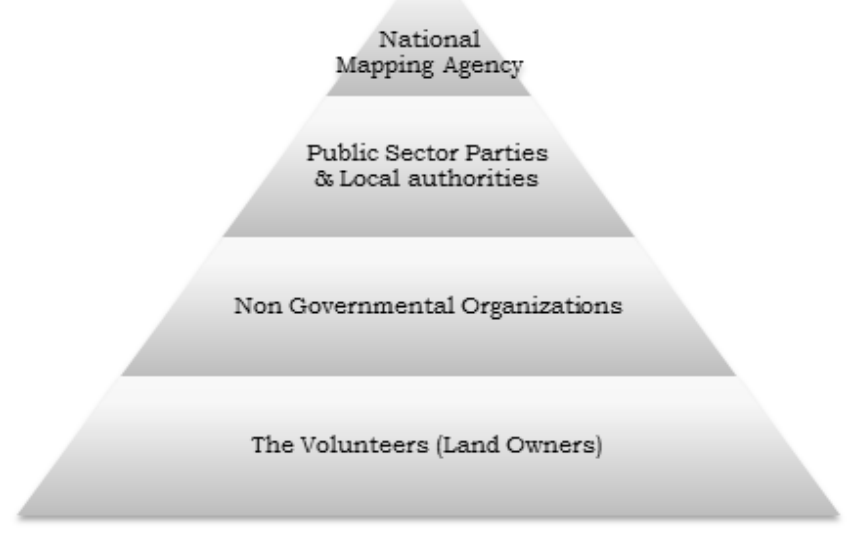

Figure 4: The stakeholders of the Project.

vehicles and facilities. The local authorities should also play a critical role in data collection and they will contribute effectively to the collaboration among teams of local people at the stage of data collection, depending on their knowledge. This ensures that participants can contribute to specific tasks and stages of the data collection.

The national mapping agency should keep a supervising role and should be actively involved in all stages of the process. Coordination of the procedure, evaluation of the result and maintenance of the data in their server are their predominant tasks.

\section{Concluding Remarks}

The model proposed here follows the trend that has been adopted during the last decade by the governmental bodies to open, inexpensive, quick and transparent processes in Land Administration Systems with the participation of citizens and the use of new technologies. The proposed model constitutes a general process that may be applied or modified according to the special needs of the official mapping agency and can be adopted in various land administration issues in various countries. Its main innovation is based on the combination of current trends and previous experience in similar case studies. Its main advantage is stated not only through the participation of citizens in important decision making policies but also through its flexibility. There are still many concerns and parameters that have not yet been identified, quality and privacy queries that a conservative part of the society poses, or problems of credibility that make governmental bodies reluctant to use it. However, it is clear that the new crowdsourcing trend is not temporary and will continue to play 
a fundamental role in this recently begun revolution. The general outcome is condensed not in a unique solution but in a general idea that should be flexible and can be easily modified based on the needs of society and the available tools and funds.

\section{Acknowledgments}

Special thanks to Professor Muki Haklay, coordinator of the World Bank project titled "Crowdsourced geographic information use in government". The findings of the previous research inspired this publication and evolved the findings in a cadastral project.

Sofia's Basiouka PhD studies are funded by the Greek State Scholarships Foundation. This support is greatly acknowledged.

\section{References}

Basiouka, S., \& Potsiou, C. 2012. VGI in Cadastre: a Greek experiment to investigate the potential of crowd sourcing techniques in Cadastral Mapping. Survey Review, 44(325): 153-161(9).

Basiouka, S., Potsiou, C., \& Bakogiannis, E. 2015. OpenStreetMap for cadastral purposes: an application using VGI for official processes in urban areas. Survey Review, DOI: http://dx.doi.org/1752270615Y-0000000011

Blaut, J. M., Stea, D., Spencer, C., \& Blades, M. 2003. Mapping as a cultural and cognitive universal. Annals of the Association of American Geographers, 93(1): 165-185.

Bogaerts, T., Williamson, I. P., \& Fendel, E. M. 2002. The Role of Land Administration in the Accession of Central European Countries to the European Union. Journal of Land Use Policy, 19(1): 29-46.

Budhathoki, N., Bruce, B., \& Nedovic-Budic, Z. 2008. Reconceptualising the role of the user of spatial data infrastructure. GeoJournal, 72(3): 149-160.

Dale, P., \& McLaughlin, J. D. 1999. Land Administration Systems Oxford University Press.

FIG. 1995. Statement on the Cadastre. Report by Commission 7 (Cadastre and Land Management), No. 11, FIG Publication.

Goodchild, M. F. 2007. Citizens as sensors: the world of volunteered geography. GeoJournal, 69(4): 211-221.

Haklay, M., Antoniou, V., Basiouka, S., Soden, R., \& Mooney, P. 2014. Crowdsourced geographic information use in government. Report to GFDRR (World Bank). London, UK.

Kaufmann, J., \& Steudler, D. 1998. Cadastre 2014 - A Vision for a Future Cadastral System. Report by Workgroup 1 of FIG Commission 7, Rüdlingen and Bern, Switzerland, FIG Publication. 
Kingsley, D. 2007. Technologies of civil society; communication, participation and mobilization. Innovation, 20(1): 19-33.

National Mapping Agency. 2011. Cadastral Survey Available at: http://www. ktimatologio.gr/ktima/EN/index.php?ID=MpuNFMi98N1Ps1QZ_EN [accessed 15 August 2011].

Seeger, C. 2008. The role of facilitated volunteered geographic information in the landscape planning and site design process". GeoJournal, 72(3): 199-213.

Sieber, R. 2007. Geoweb for social change. Available at: http://www.ncgia.ucsb. edu/projects/vgi/supp.html [Accessed 12 September 2012].

Steudler, D. 2004. A framework for the evaluation of land administration systems. Unpublished thesis (PhD), The Department of Geomatics, The University of Melbourne.

UNECE. 1996. Land Administration Guidelines. ECE/HBP/96 Sales No.E.96. II.E.7, New York and Geneva, Switzerland, United Nations publications.

UN-FIG. 1996. Bogor Declaration on Cadastral Reform. UN-FIG. United Nations Interregional Meeting of Experts on the Cadastre. Bogor, Indonesia, FIG publication No. 13A, In: Steudler, D. (Ed.) 2004 A framework for the evaluation of land administration systems. Unpublished thesis (PhD), The Department of Geomatics, The University of Melbourne.

United Nations. 1985. Conventional and Digital Cadastral Mapping. Report of the Meeting of the Ad Hoc Group of experts on Cadastral Surveying and Land Information Systems. Economic and Social Council E/CONF (Vol. 77). In: Steudler, D. (Ed.) 2014 A framework for the evaluation of land administration systems. Unpublished thesis (PhD), The Department of Geomatics, The University of Melbourne.

Williamson, I. P. 2001. Land administration "best practice" providing the infrastructure for land policy implementation. Journal for Land Use Policy, 18(4): 297-307. 